\title{
A IMPORTÂNCIA DA EAD NA FORMAÇÃO DO SUJEITO
}

BASTOS, Manoel de Jesus ${ }^{1}$

BASTOS, Manoel de Jesus. A Importância da EAD na Formação do Sujeito. Revista Científica Multidisciplinar Núcleo do Conhecimento. Ano 02, Ed. 01, Vol. 14, pp. 71-81 Janeiro de 2017. ISSN: 2448-0959

\section{RESUMO}

O surgimento dos cursos EAD no Brasil, nos últimos anos, abriram portas para possibilitar que as pessoas que não tinham condições de realizar um curso presencial, realizassem seus sonhos. A Lei de Diretrizes e Bases da Educação Nacional, favoreceu a chegada do ensino à distância aos lugares dos mais difíceis acessos, efetivando, dessa forma, a inclusão social do conhecimento, em todo país. É uma modalidade que proporciona a interatividade constante do aluno com os que fazem parte do processo de ensino. A qualidade da educação à distância vai depender da fomentação do aluno que deve buscar todas as informações essenciais à sua aprendizagem.

Palavras-Chave: Educação à Distância, Curso, Tecnológico.

\section{INTRODUÇÃO}

Nos últimos anos, os cursos EAD, tem suprido grandes carências dos indivíduos que não tiveram a oportunidade de cursar uma universidade presencial. Apesar de serem constatadas uma série de dificuldades no andamento dos cursos e-learning aqui no Brasil, certamente pela falta de ferramentas tecnológicas, proporcionando o desestímulo e o abandono por parte dos estudantes, há, ainda, um grande percentual

\footnotetext{
${ }^{1}$ Formado em Normal Superior pela UESPI (Universidade Estadual do Piauí), Pósgraduado em Supervisão Escolar pela Faculdade de Teologia Hokemãh - Fateh e Mestrando em Educação pela Anne Sullivan University.
} 
que persiste a fidelidade e permanência nos cursos à distância. É um processo que supera expectativas entre professor/aluno e o uso devido dos recursos tecnológicos possibilita avanços surpreendentes, transportando, mutuamente, as informações didáticas de forma segura e em pouco tempo.

A educação à distância tem procurado chegar aos lugares dos mais difíceis acessos e o seu espaço institucional vem se ampliando em quase todos os setores. Ao longo do processo e com o ganho de imensuráveis experiências construiu-se uma plataforma de relacionamento onde ocorre o diálogo entre aqueles que demonstram interesse de entrar no assunto. De modo que o conhecimento é efetivado desde que se demonstre fome e sede pela preciosidade.

Acredita-se, existir poucas diferenças nos resultados apresentados, estatisticamente, em relação as duas formas de instrução, levando em consideração que a educação à distância predomina na concorrência, por apresentar menor custo e um controle mais acessível. Os alunos da educação e-learning podem até apresentar preocupações com as metodologias tecnológicas, mas poderão sentir-se mais à vontade, sem ter que conviver, diariamente, com certas dificuldades de confrontos de personalidades ou grupos. Admite-se que qualquer modalidade de ensino possa apresentar as suas qualidades no processo, desde que seja levado em conta o público alvo a que se referencia. No caso das modalidades presencial e a distância, ambas exigem profissionais de perfis bastante distintos.

Para PALLOFF e PRAT, em alguns casos, a comunicação via internet tem apresentado maior eficácia que a comunicação presencial. Os relacionamentos no espaço virtual podem, muitas vezes, ser mais intensos do que a comunicação criada diretamente, ou seja, face-a-face e o fator comunicação, mais que os conteúdos apresentados, é o que gera conhecimento.

Esses conceitos ou ideias explicitam novidades para alguns educadores que deixam passar despercebido esse conjunto de recursos técnicos na comunicação. É através do diálogo eletrônico que os alunos inteiram-se uns com os outros, criando, ao longo do processo, pontes de partilhamento online. Contudo, para haver um diálogo 
colaborativo e compromisso de todos os participantes desse grupo virtual, torna-se imprescindível a intersecção do professor que incentivará a participação de todos e promoverá ambientes saudáveis e descontraentes, cujo objetivo é a permanência do interesse de todos no processo aprendizagem.

\section{ENCONTROS PRESENCIAIS NA EAD}

A educação à distância além de fornecer subsídios via internet, proporciona encontros para a realização de seminários quinzenal ou mensalmente, dependendo do curso oferecido. Durante esse tempo são tratadas as questões teóricas e metodológicas, com a promoção de palestras, debates, oficinas, abolição de dúvidas e a garantia da motivação aos cursistas, com o intuito de chegarem ao final do curso com uma bagagem suficiente que lhes permita o desenvolvimento de um trabalho com segurança e eficácia.

Uma boa formação através da EAD, vai depender da imbuição de todo o conjunto, mais precisamente, do cursando que deve buscar as informações essenciais a sua aprendizagem. Nos seminários, os cursistas dialogam, tiram dúvidas e debatem, expondo os seus pontos de vistas e procuram tirar maior proveito do lhes importa para a sua formação.

Embora faltem alguns recursos tecnológicos para a efetivação de um curso que possa atender todas as expectativas dos seus cursandos, uma vez que o analfabetismo na área de informática ainda é uma realidade, a educação à distância procura condicionálos ao tempo, flexibilizando-o de acordo a disponibilidade de cada um. O ensino a distância vem crescendo e, consequentemente, alcançando efeitos sociais marcantes, pois tem possibilitado o acesso a formação de pessoas que vivem em áreas de difícil acesso e as que não dispõem de tempo para ingresso ao horário normal de funcionamento da escola.

Num curso e-learning, é necessário que aconteçam sessões presenciais para que os alunos se conheçam, troquem informações e experiências e possam analisá-lo melhor. Nessas sessões são solicitados os devidos trabalhos científicos relacionados 
a cada disciplina ministrada pelo professor. As orientações são feitas com base nas normas da ABNT e o prazo estimado, para a entrega dos mesmos, com base nas normas da instituição, onde, posteriormente, cada aluno procederá conforme a orientação de cada professor. Da mesma forma em que os alunos são orientados, são, ao mesmo tempo, encorajados a interessar-se pelo conceito de ensinar, aprender e a refletir sobre um novo entendimento, rumo a novas conclusões. Em alguns cursos, dependendo dos objetivos e de suas normas específicas, poderão ser realizadas algumas atividades e avaliações presenciais.

\section{AS TECNOLOGIAS NA EAD NO BRASIL}

Embora não seja a única e exclusiva alternativa determinante, a tecnologia tem sido a grande parceira, associada ao desenvolvimento da educação à distância no Brasil (CARMO, 1999, não paginado). É visível o impulsionamento dos avanços tecnológicos que vem propiciando o desenvolvimento da educação à distância em nosso país. A sua isenção resultaria na impossibilidade de prosseguimento desses cursos que vem viabilizando a formação de pessoas que não tiveram a oportunidade, ou disponibilidade de tempo, de cursar em uma escola presencial.

O uso diário dos mais diversificados tipos de ferramentas tecnológicas, tem possibilitado que milhares de indivíduos tenham realizados os seus sonhos, em um curso EAD no Brasil. Tanto na área educacional quanto nas áreas profissionalizantes, o ensino a distância vem ganhando fôlego graças a essas ferramentas, consideradas indissociáveis e imprescindíveis a sua consolidação. A integração das TIC Tecnologia de Informação e Comunicação, no processo educacional é de suma importância para a sua estruturação, até porque já se fazem presentes em todas as áreas da vida social, cabendo as instituições educacionais públicas ou privadas adequá-las, no sentido de facilitar o acesso à educação, diminuindo, assim, as desigualdades sociais existentes no Brasil.

Desde os anos 70 já se oferecia cursos, de caráter compensatório, através dos meios tecnológicos (no caso, a televisão) com o intuito de viabilizar o crescimento da oferta do ensino fundamental, especialmente nos anos finas e sanar, ou pelo menos, atenuar 
as carências no ensino básico. Atualmente, as ferramentas tecnológicas utilizadas nos cursos são as mais diversificadas possíveis, desde um cartão memória a um data show. Por depender dessas ferramentas, uma pequena oscilação na internet já seria o suficiente para a obstrução do desenvolvimento de um cursista EAD.

Os limites entre tecnologia, educação e entretenimento, tendem a estreitarem-se nas modalidades contemporâneas onde o consumo das informações serão aplicados tanto ao trabalho quanto a vida afetiva e o lazer.

A questão do tempo tem sido o nó górdio dos programas $E A D$, juntamente com o material didático utilizado. Não tem sido diferente com a TV Escola. Enquanto a dimensão do espaço pode ser resolvida com materiais interativos e/ou uso de tecnologias como o telefone, o fax, o e-mail que facilitam a comunicação entre o professor e o aprendente, a questão do tempo é a mais complexa, uma vez que possui, em seu interior, dimensões e aspectos que interferem no processo educativo. (TOSCHI, 2000, não paginado)

O poder tecnológico vem contribuindo, significativamente, com o crescimento da educação à distância no Brasil e no mundo, tanto em termos de finalidades sociais, quanto em estratégias e modalidades, tendo em vista a viabilização da flexibilidade de acesso, currículos e metodologias. A EAD deixa de oferecer um ensino de caráter paliativo ou emergencial e passa a responsabilizar-se por algo de cunho e credibilidade crescente. Contudo, faz-se necessário, saudar com otimismo a obsolência acelerada, da tecnologia na construção do conhecimento, uma vez que esta tem objetivado a integração de esforços para a consolidação de educação à distância, sobretudo na formação de professores, em todos os níveis.

\section{A EAD E SUAS GARANTIAS NA LDB}

A legalidade da educação a distância surgiu graças ao decreto de № 2.494, da Presidência da República, que regulamentou o artigo $8^{\circ}$ da Lei de Diretrizes e Bases da Educação Nacional, ou seja, é prática em nosso país desde o século passado, mas 
somente no ano de 1996, é que aparece, explicitamente, como modalidade de aprendizagem prevista na LDB.

Educação à distância é uma forma de ensino que possibilita a auto aprendizagem, com a mediação de recursos didáticos sistematicamente organizados, apresentados em diferentes suportes de informação, utilizados isoladamente ou combinados, e veiculados pelos diversos meios de comunicação. (BRASIL, 1998, não paginado)

A LDB prevê no seu artigo $80, \S 4^{\circ}$ que a educação à distância gozará de tratamento diferenciado, que incluirá:

I - custos de transmissão reduzidos em canais comerciais de radiodifusão sonora e de sons e imagens e em outros meios de comunicação que sejam explorados mediante autorização, concessão ou permissão do poder público;

II - concessão de canais com finalidades exclusivamente educativas;

III - reserva de tempo mínimo, sem ônus para o poder público, pelos concessionários de canais de educação.

Entende-se, portanto, que a origem da EAD traz, como alvo principal, o favorecimento do acesso ao saber para o maior número de pessoas possível, que demonstre interesse e que esteja de acordo a sua modalidade. A sua criação teve dentre outros objetivos, reduzir as distâncias geográficas e temporais, proporcionando ao aluno a sua organização de tempo e lócus de estudo.

A educação à distância será parte natural do futuro da escola e da universidade. Valerá ainda o uso do correio, mas parece definido que o meio eletrônico dominará a cena. Para se falar em educação à distância é mister superar o ensino e a mera ilustração. Talvez fosse o caso distinguir momentos, sem dicotomia. Ensino à distância é uma proposta para socializar informação, transmitindo-a de maneira mais hábil possível. Educação à distância, por sua vez, exige aprender à aprender, elaboração e consequentemente avaliação. Pode até conferir diploma ou certificado, prevendo, momentos presenciais de avaliação. (DEMO, 1994, p. 60) 
É inadmissível pensar que a educação à distância seja uma modalidade em que permita o isolamento do aluno, mas proporcione a sua interatividade constante com todos que fazem parte do processo. Para que exista a comunicação recíproca, foi estabelecida a mão dupla entre professor/aluno com a possibilidade de interação entre ambos. Em resumo, a EAD é uma prática educativa que busca aproximar o conhecimento ao aprendiz. Para tanto, o relacionamento do aluno com o grupo do processo e com as ferramentas tecnológicas que lhes dá suporte, são, eminentemente, indispensáveis.

Os docentes da educação à distância estabelecem estratégias que contribuem com o processo de ensino aprendizagem, instigando aos alunos a necessidade participativa e a provocação de questionamentos, para a efetivação do referido processo. Portanto, o conceito "à distância", na educação deve ser relativizado, uma vez que este trata de uma educação flexível, onde o estudante se programa, preparando o seu próprio tempo, de acordo a sua disponibilidade.

\section{A EAD NA FORMAÇÃO DO SUJEITO}

Atualmente há uma infinidade de cursos via $E A D$, desde a educação básica à universidade, para aqueles que por algum motivo deixaram de cursar na etapa adequada. O Ensino Médio com Intermediação Tecnológica - EMITEC, é uma realidade nas áreas rurais, onde há maior números de indivíduos que apresentam dificuldades para fazer um curso médio presencial. Os cursos superiores que até poucos anos atrás eram sonhos, passaram a ser fatos nos dias atuais.

A exemplo, bem sucedido, de países que tem a educação como a solução para os problemas da sociedade e não mais um problema crônico dos seus cidadãos, a educação à distância tem procurado atingir o maior número possível de sujeitos com formação que Ihes dê suporte ao legítimo e pleno exercício da cidadania. Na área da pedagogia, esses cursos vem oferecendo amplas oportunidades aos docentes que almejam aperfeiçoarem-se e poderem contribuir da melhor forma possível com o processo educativo. 
Os cursos EAD ainda apontam outra vantagem relativa ao desenvolvimento que é a necessidade do sujeito adquirir conhecimento suficiente na área da informática para o domínio das ferramentas tecnológicas que Ihes são exigidas. Dessa forma, o educando EAD estaria potencializando, ainda mais, os seus conhecimentos, tendo em vista que a imensurabilidade de sua importância nos dias atuais. Tudo isso são formas de lidar com a construção e a efetivação do conhecimento e seus impulsos, que exigem estratégias, ações inovadoras e inéditas para os sujeitos.

No entanto, entende-se que a educação à distância origina de uma visão de prática de liberdade e desenvolvimento cultural na construção do conhecimento do sujeito e que depende do uso múltiplo de tecnologias para a consolidação do seu avanço. É admissível que a formação do indivíduo, através da educação à distância, deixou de ser algo experimental e passou a ser uma realidade consolidada no Brasil e no mundo e trouxe, além das transformações, a realização de muitos sonhos que antes pareciam impossíveis.

Com a oferta da facilidade de acesso as múltiplas informações possibilitadas pela internet, um dos maiores desafios atuais para o professor de educação à distância é a orientação norteadora do pensamento e a escolha essencial de uma gama de fontes informativas disponíveis.

$\mathrm{Na}$ educação à distância, os alunos deixaram de ser receptores e os professores meros emissores, tendo em vista, que ambos passaram a ser os verdadeiros protagonistas nesse delicado processo, com a impregnação do estabelecimento de relações mútuas, na troca de cooperação e construção em comum. Essa interação entre professores e estudantes na EAD torna-se necessária para gerar a motivação de resolver os desafios que surgem durante o processo.

$\mathrm{Na}$ formação do sujeito, através da educação à distância, o professor tem tarefas similares as do professor de cursos presenciais, porém há om outro papel de sua verdadeira incumbência que é o de manter o contato online com os alunos, mediar e facilitar o processo do ensino aprendizagem. Nesse processo estão envolvidos, além dos professores, programadores, gestores, coordenadores do curso e dos 
professores, que atuam, reciprocamente, para a garantia da qualidade do ensino. É um exemplo de trabalho compartilhado com intenções qualitativas e preservação da credibilidade.

Portanto, para o desenvolvimento de um curso EAD, é imprescindível a capacidade interativa, objetividade e clareza nas informações, animação nos debates de cada disciplina e controle emocional e racional dos educandos. Esses itens são relevantes para o sucesso do processo, pois o curso só alcançará os seus objetivos quando tudo isso for levado em conta.

Os cursos de formação na modalidade EAD, tem sido verdadeiras alternativas para aqueles que sonhavam ter uma formação mas que não dispunham das condições necessárias exigidas pelo ensino presencial, tampouco disponibilidade de tempo ao calendário da instituição. (Grifo nosso)

Segundo Gatti, "educar e educar-se à distância requer condições muito diferentes da escolarização presencial". A educação à distância rompe os limites de temporaneidade, privando os participantes do contato físico constante. A ausência da figura do professor que pudesse chamar a atenção do aluno, obviamente espera do aluno maior determinação e preservação nos seus hábitos estudantis e novas estratégias de lidar com suas dificuldades.

Para que o processo de formação do sujeito possa acontecer de forma efetivada é necessário que os professores envolvidos na educação à distância estejam preparados para trabalhar com a multimídia e equipamentos tecnológicos, desenvolvendo a melhor interlocução via canais de comunicação, proporcionando, assim, o desenvolvimento dos alunos por quem mantêm a interatividade. De todos os requisitos que um programa EAD necessita, a interatividade é uma das mais preciosas para o seu sucesso, por ser uma qualidade social, indispensável a qualquer programa de educação à distância. 


\section{A IMPORTÂNCIA DO EAD NA FORMAÇÃO DO SUJEITO}

O ensino à distância tem o seu desenvolvimento por meio de atividades que não exige, necessariamente, a presença do aluno e do professor no mesmo lócus e na mesma hora, simultaneamente. O aluno poderá receber informações e o material necessário, pelos canais tecnológicos: telefone, internet, e-mail, site, satélite, TV, etc.

Tanto os cursos EAD, como os presenciais, possuem normas com as exigências de frequência, exames, tarefas, repetências, avaliações, tempo de dedicação, entre outros, tornando mais fácil pelo fato de oferecer mais liberdade para os seus educandos condicionarem aos seus ritmos de estudos. Nessas circunstâncias, os alunos recebem liberdade de planejar a rotina que caiba no seu tempo, dedicando as aulas nos horários que Ihes convier.

Atualmente, alargou-se a possibilidade da relação de cursos à distância em, praticamente, todos os níveis. Geralmente, tem preços menores que os cursos presenciais, sendo mais convenientes para os alunos que não possuem os requisitos exigidos por um curso presencial.

A LDB, prevê as suas existências, tanto na educação básica quanto na superior e garante a validade dos seus diplomas equivalentes aos de um curso presencial. Os cursos EAD, tanto para o ensino médio quanto para o técnico, graduação ou pósgraduação, são projetados com duração igual a modalidade presencial.

\section{CONSIDERAÇÕES FINAIS}

Conclui-se, portanto, que os cursos de ensino à distância tem contribuído com as grandes transformações educacionais nos últimos anos, com a oferta de possibilidades para as pessoas que almejavam uma formação e não dispunham da disponibilidade de tempo exigido em um curso presencial. Muitos são os profissionais que concluíram um $\mathrm{AD}$ e, atualmente, estão inseridos no mercado de trabalho, dando a sua parcela de contribuição para o desenvolvimento de nosso país. 
Admite-se que as instituições de cursos a distância no Brasil, efetivou a inclusão social dos menos favorecidos à sociedade letrada, pela democratização e favorecimento da acessibilidade aos meios de comunicação tecnológicos. O sucesso de um curso EAD está agora nas mãos e nas mentes daqueles que tem sonhos possíveis e criam ações para consolidá-los, apostando em suas próprias carreiras, sem confrontos, mas acreditando na evolução das relações interpessoais.

Em outras palavras, a educação à distância é um processo que vem descentralizando o acesso e socializando, democraticamente, oportunidades para todos, com intensidade e efetivação de benefícios oferecidos através dos mais admiráveis meios tecnológicos de comunicação, postos à disposição do conhecimento. Esse processo é uma atividade educativa influenciada pela dinâmica tecnológica por todos que fazem parte dela.

E para colaborar com a busca da qualidade e seriedade do ensino à distância, criouse a ABED-Associação Brasileira de Educação à Distância, que juntamente com outros interlocutores, analisam e refletem a respeito do andamento do processo.

\section{REFERFÊNCIAS}

BELANGER, F.; JORDAN D. J. (2000) - Evaluation and Implementation of Distance Learning:Technologies, Tools and Techniques. USA: IdeaGroup Publishing, 2000.

CARMO, H. Ensino Superior a Distância. Lisboa: Universidade Aberta, 1998.

GATTI, Bernadete A. Critérios de Qualidade. In: Almeida, M. E; MORAN, J. M. (Org). Integração das Tecnologias na Educação. Série Salta para o Futuro, Secretaria de Educação a Distância. Brasília: Ministério da Educação, Seed, 2005. p. 143-145.

LDB - Lei de Diretrizes e Bases da Educação Nacional / Lei oㅜ 9.394 de 20 de dezembro de $1996-11^{\underline{a}}$ ed.

PALLOFF \& Keith PRAT, Building Learning Communities in Cyberspace (1999). 
Revista Brasileira de Educação Aberta e a Distância da ABED, em sua versão eletrônica: Brasília, março 2004. 